\title{
Systemic absorption of topical and subconjunctival gentamicin
}

\author{
G. E. TROPE, ${ }^{1}$ J. R. LAWRENCE, ${ }^{2}$ VALERIE M. D. HIND, ${ }^{1}$ AND \\ ANNE EVERDEN ${ }^{3}$ \\ From the Departments of ${ }^{1}$ Ophthalmology, ${ }^{2}$ Materia Medica, and ${ }^{3}$ Pharmacy, Stobhill General Hospital, \\ Glasgow
}

SUMMARY Ten patients received ocular gentamicin therapy topically or subconjunctivally. Systemic absorption was not detected after topical use but was detected after subconjunctival administration. The relative safety of ocular gentamicin therapy is discussed and the literature is reviewed.

Gentamicin instilled topically as eyedrops or subconjunctivally is commonly used to treat eye infections. It is well known that gentamicin can produce ototoxicity, particularly in patients with renal disease, as this drug is almost entirely excreted by the kidney (Goodman and Gilman, 1975). Previous experiments in man have indicated systemic absorption following subconjunctival use, but the results are conflicting (Furgiuele, 1970; Mathalone and Harden, 1972). We believe this to be the first attempt to evaluate the systemic absorption of gentamicin following both topical and subconjunctival administration.

\section{Patients and methods}

Ten patients were divided into two groups. Group $I$ consisted of 4 children and 1 adult who had been admitted for routine squint surgery. They were treated with topical gentamicin drops (Genticin $0 \cdot 3 \%$ drops) instilled 2-hourly into both eyes for a 5-day period until between 20 and $38 \mathrm{mg}$ of the drug had been administered (Table 1). Urine was collected over 24 hours after the last dose was administered and analysed for gentamicin by bacteriological (Alcid and Seligman, 1973) and radioimmuno assay (RIA) techniques.

Group II consisted of 5 adult post-cataract patients who were given either 10 or $20 \mathrm{mg}$ of gentamicin subconjunctivally. Blood was removed 1,2 , and 4 to 6 hours after subconjunctival injection. After centrifugation the serum concentration of gentamicin was determined by RIA using a kit supplied by Diagnostic Products Corporation, Los Angeles, Ca 70064, USA. This assay uses ${ }^{125} \mathrm{I}$

Correspondence to Dr G. E. Trope, Tennent Institute of Ophthalmology, Western Infirmary, Glasgow G11 6NT
Table 1 Total dose of gentamicin applied to both eyesgroup I

\begin{tabular}{lll}
\hline Patient & Age & Total dose $(\mathrm{mg})$ \\
\hline 1 & 39 & 27.00 \\
2 & 8 & 20.00 \\
3 & 8 & 23.00 \\
4 & 3 & 38.00 \\
5 & 3 & 20.00 \\
\hline
\end{tabular}

gentamicin and had a coefficient of variation in our hands from $10.0 \%$ at $0.5 \mu \mathrm{g} / \mathrm{ml}$ to $6.5 \%$ at $10 \mu \mathrm{g} / \mathrm{ml}$. The detection limit of this assay was $0.05 \mu \mathrm{g} / \mathrm{ml}$ when drug-free serum was used to prepare standards.

\section{Results}

Group I. No significant amounts of gentamicin were detected in the urine from any of the 5 patients on topical drops. This applied to the bacteriological method of antibiotic detection, the lower limit of detection being $0.5 \mu \mathrm{g} / \mathrm{ml}$. With the radioimmuno assay technique non-specific gentamicin binding occurred when urine was used as a control, so that this technique was not applicable to the assay of gentamicin in urine.

Group II. Antibiotic was present in detectable concentration in the serum of all 5 patients tested. Table 2 summarises the serum levels of gentamicin attained in these patients.

\section{Discussion}

Gentamicin is very poorly absorbed from the gastrointestinal tract (Goodman and Gilman, 1975), so 
Table 2 Total dose applied to both eyes with serum concentrations of drug-group II

\begin{tabular}{lllll}
\hline Patient no. & $\begin{array}{l}\text { Dose } \\
(\mathrm{mg})\end{array}$ & $\begin{array}{l}1 \text { hour } \\
(\mu \mathrm{g} / \mathrm{ml})\end{array}$ & $\begin{array}{l}2 \text { hours } \\
(\mu \mathrm{g} / \mathrm{ml})\end{array}$ & $\begin{array}{l}4 \text { to } 6 \text { hours } \\
(\mu \mathrm{g} / \mathrm{ml})\end{array}$ \\
\hline 1 & 10 & 0.20 & 0.20 & Nil \\
2 & 10 & 0.20 & 0.10 & Nil \\
3 & 10 & 0.40 & 0.30 & Nil \\
4 & 20 & 0.98 & 0.76 & 0.59 \\
5 & 20 & 0.58 & 0.51 & 0.30 \\
\hline
\end{tabular}

systemic absorption must take place directly into the circulation from the eye. The total doses of gentamicin used in group I patients represent $43 \frac{1}{2}$ days of topical therapy had the drug been applied 3 times daily $(0.135$ to $0.172 \mathrm{mg}$ gentamicin per 0.05 $\mathrm{ml}$ drop of Genticin) (personal communication, Nicholas Laboratories). Our inability to detect significant systemic absorption from this group of patients suggests that even in patients with moderate renal impairment long-term low-dose use of gentamicin eyedrops is relatively safe. We were unable to find any reported cases of topical gentamicin eyedrops causing disease of the vestibular apparatus.

Systemic absorption from subconjunctival injection has been confirmed in the patients of group II. We were able to detect significant blood levels 2 hours after injection in all our patients. Although the levels we recorded are higher than those detected by Mathalone and Harden (1972), they are somewhat lower than those reported by Furgiuele (1970). This latter worker detected high plasma levels 4 hours after the initial injection of $10 \mathrm{mg}$ of gentamicin, while we were unable to detect any drug at this time. Data from Case 4 showed gentamicin had a half life ( $\left.\mathrm{T} \frac{1}{2}\right)$ after subconjunctival administration of 4.2 hours and a total body clearance of $83 \mathrm{ml} / \mathrm{min}$. These figures are comparable to published figures after intramuscular and intravenous injection (Sawchuk et al., 1977) and confirm the reliability of the method we used.
To produce significant ototoxicity gentamicin should reach serum levels of 4 to $5 \mu \mathrm{g} / \mathrm{ml}$ for a period of 7 to 10 days (Mawer et al., 1974). Thus from the results reported in this paper it is clear that gentamicin is a safe antibiotic to use both topically and subconjunctivally. Large subconjunctival doses are unlikely to produce ototoxicity, as the highest dose of plasma gentamicin we could detect was $0.98 \mu \mathrm{g} / \mathrm{ml}$ after a subconjunctival injection of $20 \mathrm{mg}$.

\section{Conclusion}

Gentamicin would be unlikely to produce potentially toxic plasma levels after topical or repeated subconjunctival administration in doses commonly used in ophthalmological practice. This fact is confirmed by the lack of data in the literature connecting ototoxicity with ocularly administered gentamicin. Further studies are indicated to determine how systemic absorption of the drug is affected in the acutely inflamed eye.

We thank Dr Stevenson and Mr Smart for performing the bacteriological assays, $\mathrm{Mr} \mathrm{H}$. H. Fawzi and $\mathrm{Dr}$ J. L. Jay for allowing us to study their patients, and Professor W. S. Foulds and Dr W. Lee for advice while preparing this paper.

\section{References}

Alcid, D. U., and Seligman, S. J. (1973). Simplified assay of gentamicin in the presence of other antibiotics. Antimicrobial Agents and Chemotherapy, 3, 559-561.

Furgiuele, F. R. (1970). Penetration of gentamicin into the aqueous humour of human eyes. American Journal of Ophthalmology, 69, 481-483.

Goodman, G., and Gilman, L. S. (1975). Pharmaceutical Basis for Therapeutics, 5th edn. Baillière Tindall: London.

Mathalone, M. B. R., and Harden, A. (1972). Penetration and systemic absorption of gentamicin after subconjunctival injection. British Journal of Ophthalmology, 56, 609-612.

Mawer, G. E., Dobbs, S. M., Ahmad, R., and Tooth, J. A. (1974). Experience with a gentamicin nomogram. Postgraduate Medical Journal, Supplement 7, 50, 31-33.

Sawchuk, R. J., Zaske, D. E., Cipolle, R. J., Wargin, W. A., and Strate, R. G. (1977). Kinetic model for gentamicin dosing with the use of individual patient parameters. Clinical Pharmacology and Therapeutics, 21, 362-369. 